\title{
Distribution of polycyclic aromatic hydrocarbons in sediments from the Changjiang River
}

\author{
Liang Huang ${ }^{1, a}$ \\ ${ }^{1}$ College of Chemistry and Environmental Engineering, Jiujiang University, Jiujiang 332005, China \\ ahuangliang2002@126.com
}

Keywords: the Changjiang River; sediment; polycyclic aromatic hydrocarbons

\begin{abstract}
Concentrations of polycyclic aromatic hydrocarbons (PAHs) were determined in the sediments from the main stream and the tributary of the Changjiang River. PAHs contents in the sediments from the Changjiang River ranged from $10.31 \mathrm{ng} / \mathrm{g}$ to $1239 \mathrm{ng} / \mathrm{g}$, which were most likely related to human activities. Meanwhile, these results were lower than that of polluted area. PAH isomer ratios showed that PAHs were derived primarily from combustion, and minor amounts of PAHs are from direct input of petroleum.
\end{abstract}

\section{Introduction}

Polycyclic aromatic hydrocarbons (PAHs) are one of the most important classes of organic contaminants, which are considered the most widespread considered highly dangerous to the environment. Due to their persistent, toxic, mutagenic and carcinogenic characteristics ${ }^{[1,2]}$, the source and distribution of PAHs have been widely investigated in the environment, e.g. water, sediment and soil ${ }^{[3,4]}$.

The Changjiang River is one of the longest River in the world, which has attracted many concerns as a result of rapidly increasing environmental pressure of huge pollutants. It was estimanted that emissions of $\mathrm{BC}$ from the provinces surrounding the Changjiang River were $9.3 \times 10^{3} \mathrm{t} / \mathrm{yr}$, which accounted for $36.8 \%$ from China ${ }^{[5]}$. In this study, we analyzed previously collected sediments from the Changjiang River. The objectives of the present study were to (1) quantify the presence of PAHs in the sediments, and (2) understant sources of PAHs in the sediments of the Changjiang River.

\section{Method}

\subsection{Study area and sample collection}

Surface sediment samples were collected from the Yangtze River drainage during the investigation of the Yangtze River in September-October, 2009 (Fig. 1). Sediment samples were dug from the bottom or waterside of the river. All samples were stored in the freezer with $-20{ }^{\circ} \mathrm{C}$ and were oven-dried at 60

${ }^{\circ} \mathrm{C}$ in laboratory.

\subsection{Quantification of PAHs}

PAHs were determined by methods decribed in detail elsewhere ${ }^{[6]}$. After Soxhlet extraction, purification with silica gel and dimethylformamide- pentane partitioning, the recoveries of internal standards were $80-110 \%$ for heavier PAH $(\mathrm{m} / \mathrm{z}=178-278)$ and $<60 \%$ for ligher PAH ( such as Naphthalene, Acenaphthylene, and Fluorene). To calculate the total of PAHs (TPAH), the following PAHs were used: phenanthrene (Phe), anthracene(An), 1-Methylphenanthrene(Mphe) ,fluoranthene(Fl), pyrene(Py), benzo(a)anthracene(BaA), chrysene/ triphenylene(Chry), benzo(b)fluoranthene(BbF), benzo(k)fluoranthene(BkF), benzo(e)pyrene(BeP), benzo(a)pyrene(BaP), indeno(1,2,3- cd)pyrene(Ip), dibenzo(a,h)anthracene(DhA), and benzo(ghi)perylene(BghiP). 




Fig. 1. Map of sampling loctions in the Changjiang River from China

\section{Result and discussion}

\subsection{Concentrations of PAHs in surface sediments from the Changjiang River}

The PAHs distribution in all sediment samples from the Changjiang River, which ranged from $10.31 \mathrm{ng} / \mathrm{g}$ to $1239 \mathrm{ng} / \mathrm{g}$, with an average of $178.0 \pm 272.2 \mathrm{ng} / \mathrm{g} \mathrm{mg} / \mathrm{g}$ (Fig. 2), which were agreement with the results (213.8-550.3 ng/g) reported by Xu et al. ${ }^{[7]}$. The variation of PAHs contents were most likely related to human activities. For example, there were two locations whereTPAH concentrations were much higher than other areas. One was XJ near polluted Xiangjiang. The other was YZ near Yangzhou, where industry activities were high. Compared to the data reported from other studies, PAHs content determined in these sediments was was similar to the values reported for other riverine or coastal sediments, such as Xiamen Harbour (195-675ng/g) ${ }^{[8]}$ and Minjiang Estuary (174-817 ng/g) ${ }^{[9]}$, but lower than the values in sediments from polluted areas, such as New York harbor $^{[10]}$ and Singapore's Coast (13630- $\left.84920 \mathrm{ng} / \mathrm{g}\right)^{[11]}$.

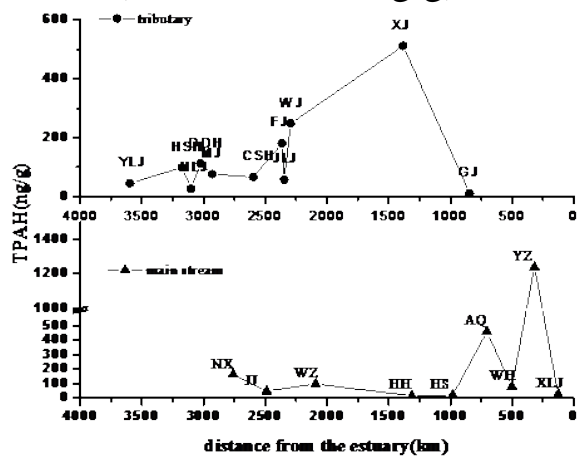

Fig. 2 PAHs contents of the sediments collected from the Changjiang River

\subsection{Determination of PAH sources for the Changjiang River}

Molecular ratios such as Mphe/Phe, $\mathrm{An} /(\mathrm{Phe}+\mathrm{An}), \mathrm{Fl} /(\mathrm{Fl}+\mathrm{Py}), \mathrm{BaA} /(\mathrm{BaA}+\mathrm{Chry})$ and $\mathrm{IP} /(\mathrm{IP}+\mathrm{BghiP})$ have been used to identify possible sources of PAHs ${ }^{[12-15]}$. For example, $\mathrm{Fl} /(\mathrm{Fl}+\mathrm{Py})>0.5$ implies combustion of coal and biomass, $0.4-0.5$ implies petroleum combustion, and $<0.4$ implies petroleum. An An/(Phe + An) ratio of 0.1 is defined as the petroleum/combustion transition point. Ratio of $\mathrm{BaA} /(\mathrm{BaA}+\mathrm{Chry})<0.2$ implies petroleum, 0.2-0.35 indicates either petroleum or combustion, and $>0.35$ implies combustion. IP/(IP+BghiP) $<0.2$ indicates petroleum, $0.2-0.5$ petroleum combustion, $>0.5$ combustion of coal or biomass. Mphe/Phe $>1$ indicates petroleum, and $<1$ implies combustion (Yunker et al., 2002).

As shown in Fig. 3, ratios of Mphe/Phe in most stations were lower than 1, strongly indicating the preponderance of combustion processes. Meanwhile, ratios of $\mathrm{An} /(\mathrm{Phe}+\mathrm{An})$ in the sediments were higher than 0.1, clearly suggesting sources from the combustion of grass/wood/coal. Ratios of Mphe/Phe in NLJ, FJ, JL and XJ $(<1)$ suggested that PAHs may be due to occasional petroleum contamination. Ratios of $\mathrm{Fl} /(\mathrm{Fl}+\mathrm{Py})>0.5$ and $\mathrm{IP} /(\mathrm{IP}+\mathrm{BghiP})>0.2$ may suggest a combination of grass, wood, coal and petroleum combustion. In summary, the PAH isomer ratios shows that PAHs in the Changjiang River sediments are derived primarily from combustion, and minor amounts of 
PAHs are from direct input of petroleum.
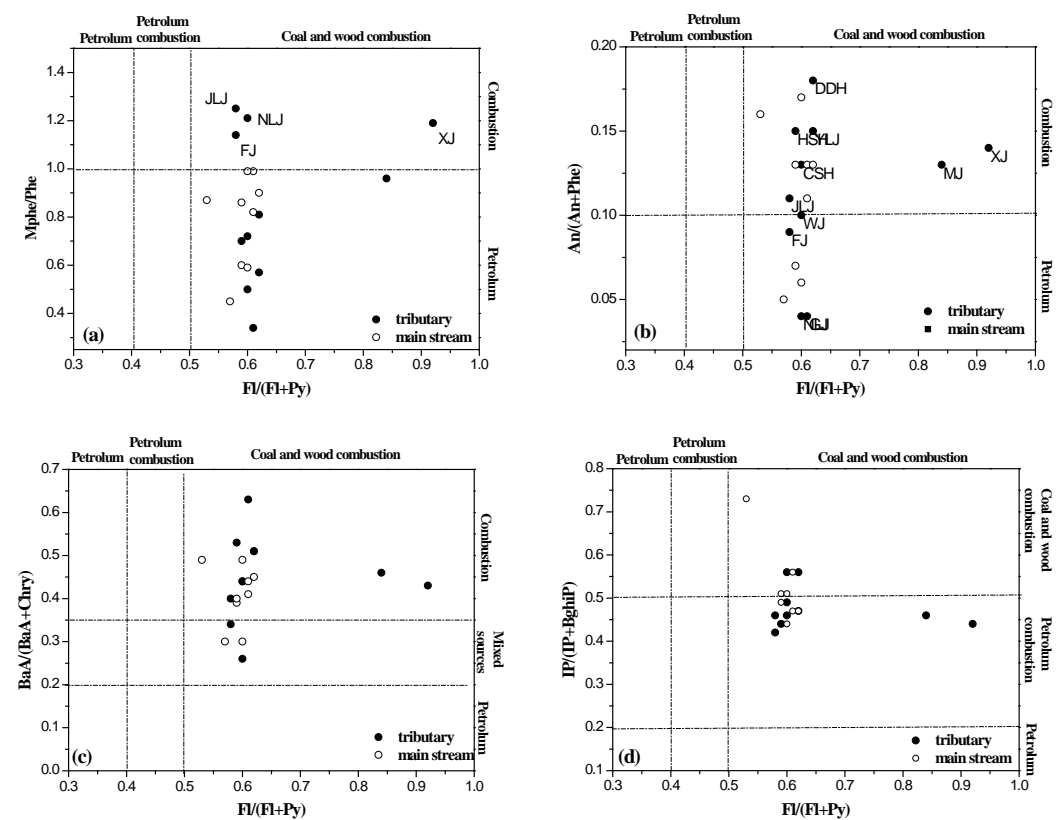

Fig. 3 Plots for the ratios of Mphe/Phe vs. Fl/(Fl+Py), An/(An+Phe) vs. Fl/(Fl+Py), $\mathrm{BaA} /(\mathrm{BaA}+\mathrm{Chry})$ vs. Fl/(Fl+Py), IP/(IP+BghiP) vs. Fl/(Fl+Py).

\section{Conclusions}

(1) PAHs contents in the sediments from the Changjiang River ranged from $10.31 \mathrm{ng} / \mathrm{g}$ to 1239 ng/g, which were most likely related to human activities. Meanwhile, these results were lower than that of polluted area, eg. New York harbor and Singapore's Coast.

(2) PAH isomer ratios showed that PAHs in the Changjiang River sediments were derived primarily from combustion, and minor amounts of PAHs are from direct input of petroleum.

\section{Acknowledgments}

This work was supported by the National Natural Science Foundation of China (No. 40830850).

\section{Refereces}

[1] P.F. Landrum, B.J. Eadie, W.R. Faust. Toxicokinetics and toxicity of a mixture of sediment-associated polycyclic aromatic hydrocarbons to the amphipod Diporeia sp[J]. Environmental Toxicology and Chemistry. 1991, 10(1): 35-46.

[2] T.M. Penning. Dihydrodiol dehydrogenase and its role in polycyclic aromatic hydrocarbon metabolism[J]. Chemico-Biological Interactions. 1993, 89(1): 1-34.

[3] G. Shrestha, S.J. Traina, C.W. Swanston. Black Carbon's Properties and Role in the Environment: A Comprehensive Review[J]. Sustainability. 2010, 2(1): 294-320.

[4] L. Liu, J. Wang, G. Wei, et al. Polycyclic aromatic hydrocarbons (PAHs) in continental shelf sediment of China: Implications for anthropogenic influences on coastal marine environment[J]. Environmental Pollution. 2012, 167(0): 155-162.

[5] Y.X., Zhang. Polycyclic aromatic hydrocarbons in China: emission, atmospheric transport and lung cancer rish [D]. Beijing University, 2010. In Chinese.

[6] M. Mandalakis, Y. Zebühr, Ö. Gustafsson. Efficient isolation of polyaromatic fraction from aliphatic compounds in complex extracts using dimethylformamide-pentane partitionings[J]. Journal of Chromatography A. 2004, 1041(1-2): 111-117.

[7] S.F. Xu, X. Jiang, L.S., Wang, et al. Polycyclic aromatic hydrocarbons pollutants in sediments 
of the Yangtze River and the Liaohe River [J]. China Environmental Science. 2000, 20(2): 128-131. In Chinese.

[8] Zhou J L, Hong H, Zhang Z, et al. Multi-phase distribution of organic micropollutants in Xiamen Harbour, China[J]. Water Research. 2000, 34(7): 2132-2150.

[9] D.X., Yuan, D.N., Yang, M.Chen, et al. Concentrations and distribution of Polycyclic aromatic hydrocarbons and organo-chlorides in surface sediemnt of Xiamen Western Harbour and Minjiang Estuary[J]. Acta Scientiae Circumstantiae. 2001, 21(1): 107-112. In Chinese.

[10] B. Yan, T.A. Abrajano, R.F. Bopp, et al. Combined application of [delta]13C and molecular ratios in sediment cores for PAH source apportionment in the New York/New Jersey harbor complex[J]. Organic Geochemistry. 2006, 37(6): 674-687.

[11] C. Basheer, J.P. Obbard, H.K. Lee. Persistent Organic Pollutants in Singapore's Coastal Marine Environment: Part II, Sediments[J]. Water Air and Soil Pollution. 2003, 149: 315-325.

[12] B.R.T., Simoneit. Application of Molecular Marker Analysis to Vehicular Exhaust for Source Reconciliations[J]. International Journal of Environmental Analytical Chemistry. 1985, 22(3-4): 203-232.

[13] M. R., Bin Abas, B.R.T Simoneit, V. Elias, et al. Composition of higher molecular weight organic matter in smoke aerosol from biomass combustion in Amazonia[J]. Chemosphere. 1995, 30(5): 995-1015.

[14] H.H., Soclo, P., Garrigues, M., Ewald. Origin of Polycyclic Aromatic Hydrocarbons (PAHs) in Coastal Marine Sediments: Case Studies in Cotonou (Benin) and Aquitaine (France) Areas[J]. Marine Pollution Bulletin. 2000, 40(5): 387-396.

[15] M.B., Yunker, R.,W., Macdonald, R. Vingarzan, et al. PAHs in the Fraser River basin: a critical appraisal of PAH ratios as indicators of PAH source and composition[J]. Organic Geochemistry. 2002, 33(4): 489-515. 